\title{
Incremental forming process strategy variation analysis through applied strains
}

\author{
Fabio Andre Lora ${ }^{1 *}$ and Lirio Schaeffer ${ }^{2}$
}

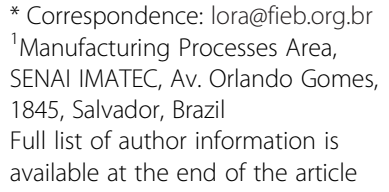

* Correspondence: lora@fieb.org.br ${ }^{1}$ Manufacturing Processes Area, SENAI IMATEC, Av. Orlando Gomes, 1845, Salvador, Brazil Full list of author information is available at the end of the article

\begin{abstract}
Nowadays, different studies on Incremental Sheet Forming have been taken due to the increasing demand for flexible manufacturing processes. This process is applicable in different areas, such as prototyping and the production of small batches of parts, always searching for lower manufacturing costs. This work analyzes how the variation of the process strategies (punch diameter and the vertical step down) influences the workpieces strain ends. These experimental studies were compared to the numerical simulation. The results found show concordance between simulated and experimental results.
\end{abstract}

Keywords: Incremental forming; Forming strategy; Numerical simulation

\section{Background}

Over the last decades, the forming area has improved its knowledge, both in terms of the materials used as well as in the flexibility and process cost reduction. The Incremental Sheet Forming (ISF) is basically focused on the production of small batches of parts, fast prototyping with process flexibility and reduced operational cost (Jeswiet 2005 and Arruda 2010). The cost reduction is focused on the need to manufacture a low cost material die and also be partially applied to the process, according to Kwiatkowski et al. (2010), Hirt et al. (2004) and Bambach (2010). The ISF is characterized by through the punctual application of load over the metal sheet performing repeated strains. Kopac and Kampus (2005) and Lora et al. (2013) comments that this type of strain applied to the workpiece, makes great strains occur in the material, far greater than the strains of the conventional processes.

As a failure criterion for sheet metal forming process, commonly the Forming Limit Diagram (FLD) in combination with a forming limit curve (FLC) is used. Among the tests that can define an FLC, there is the Nakajima methodology, which presents good reliability in the results. A conventional FLC cannot be directly applied to ISF process as a failure criterion due to strains in ISF process be highly superior and have no linear strain path. Silva et al. (2010) and Kuzman et al. (2010) find maximal strains superior to FLC when applied the ISF process in the metal sheet forming.

The need to search for a new strain limit for the materials applied to ISF process has occurred, and studies have been developed in the last decade defining parameters that influence the material drawability, according to Jeswiet et al. (2005). This work evaluates the strategies of the ISF process through variation of the vertical step down and 


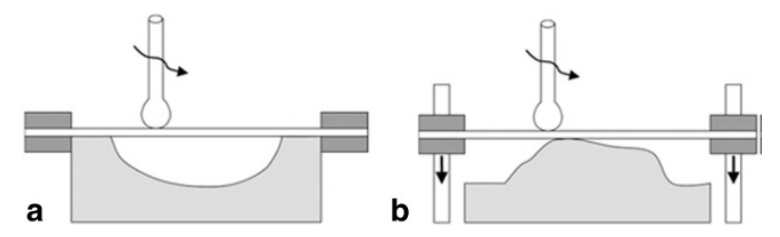

Figure 1 Variations of Incremental process. a. Negative process; b. Positive process (Allwood et al. 2006).

punch diameter variations, obtaining information about the true strains applied to the material.

\section{Incremental forming}

The incremental forming process consists on the application of load with a spherical punch in the metal sheet, introducing local strains. The sum of the punctual strains determines the final geometry of the workpiece. The incremental forming processes can be classified as: Single Point Forming (SPF) and Two Point Forming (TPF), being the latter with total or partial support. An additional sub categorization can be taken by negative and positive forming. In the negative type, the application of the force in the cavity to be formed will be in the inside, while in the positive, it will be applied outside. These types of secondary processes subcategories of TPF are illustrated in Figure 1 for TPF.

The processes classification in SPF and TPF is due to the presence or absence of a die/inferior base to the workpiece. The positive process can also be divided in: complete or partial support and it is defined by the embracing of the die under the formed workpiece. It can be observed in Figure 2 the illustration of the three processes.

An important point to be emphasized is the need/capacity of the blank holder to move in vertical direction. As in the TPF case, the blank holder has to follow the punch movement towards the increment; this way strains will happen only in the punch contact region.

\section{Methods}

a. Experimental procedure

The tests were conducted on a simple straight line geometry, in which varied forming strategies were applied. The sheets were engraved with circles separated by

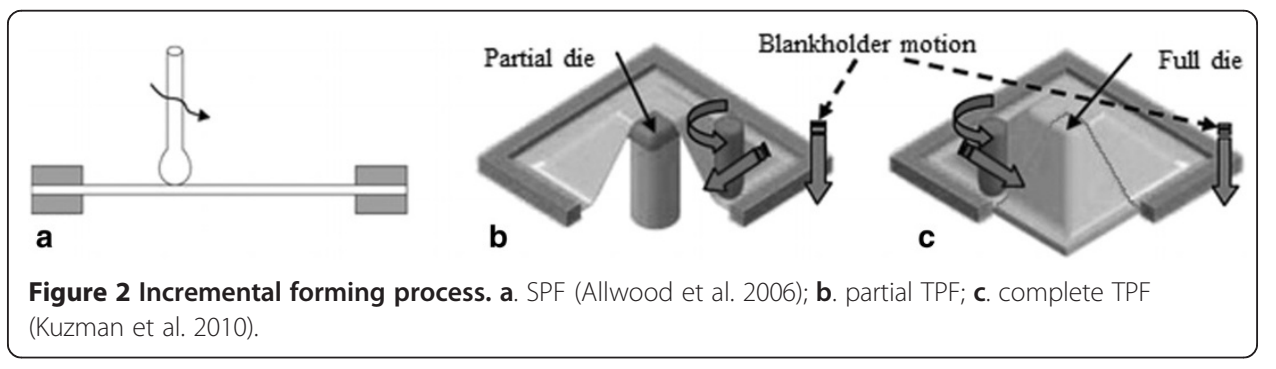


Table 1 Parameters analyzed in the experiments

\begin{tabular}{lcc}
\hline Test \# & Parameter \\
\hline & Punch diameter $\left(P_{\varnothing}\right)[\mathrm{mm}]$ & Vertical step down $(\mathrm{p})[\mathrm{mm}]$ \\
1 & 30 & 1 \\
2 & & 2,5 \\
3 & 20 & 1 \\
4 & & 2,5 \\
\hline
\end{tabular}

$2 \mathrm{~mm}$ (from the centers) through an electrochemical corrosion and an electric current. This corrosion applied to the material does not damage the same.

All experiments were conducted on a DC04 sheet blank (thickness $=1 \mathrm{~mm}$ ) with a work space of $360 \times 70 \mathrm{~mm}^{2}$ (length $\mathrm{x}$ width). Table 1 summarizes all applied strategies, went always a feed rate of $2000 \mathrm{~m} / \mathrm{min}$ was used.

The experiments were done with the horizontal motion strategy and the " $\mathrm{Z}$ " increment with a $45^{\circ}$ angle from the punch. In Figure 3, it can be observed the forming strategy.

The tests were applied using the SPF negative process, i.e., only the punch was in touch with the strained end of the sheet. In Figure 4, it can be observed how the tooling was inserted in the equipment AMINO, model DLNC RB and in Figure 5a the workpiece formed in test \#1.

All tests were interrupted when rupture/rip occurred and were replayed three times. In all tests it was possible to note that this rupture always occurred in the workpiece ends, in the place where the "Z" increment occurs. In Figure 5b, from the inferior view, and in Figure 5c, from the superior view it can be observed the rupture in the workpiece.

b. Numerical simulation

As incremental forming is a progressive sheet metal manufacturing process, characterized by large displacements and large located strains, the explicit solution scheme was adopted. The investigated process was numerically simulated using explicit code LS-DYNA. The explicit FEM is adequate to analyze the manufacture of simple geometries as cones or pyramids, according to Bambach and Hirt (2007) and Dejardin et al. (2010). The parameters used in the numerical simulation were the same used in the experiment, as shown in Table 1. Figure 6 illustrates the assembly of the component in the software.

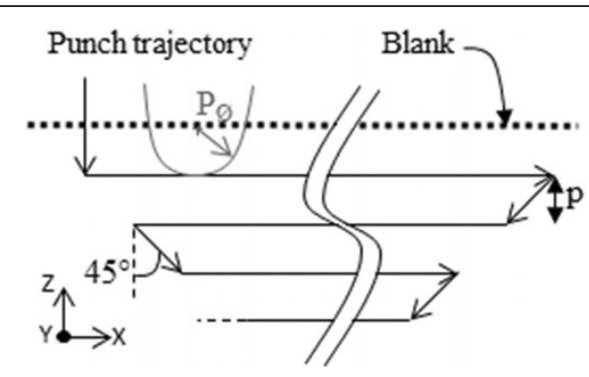

Figure 3 Displacement/forming strategy done by the punch. 


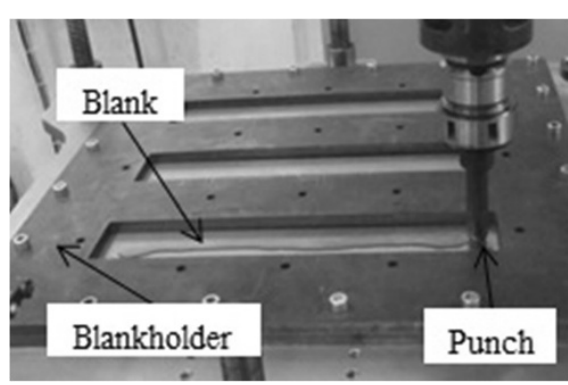

Figure 4 Tooling inserted in the equipment.

The blankholder, punch and die were assumed rigid. A Coulomb model was considered for frictional $(\mu=0.1)$ actions. The Gauss integral was adopted at thickness direction with 3 points integration. The mesh was adopted $2 \times 2 \mathrm{~mm}$ quadratic. Three integral dots and four nodes linear Belytschko-Tsay shell element were used. The material model of Barlat 36 with anisotropic materials under plane stress conditions was adopted. The exponent " $\mathrm{m}$ " in Barlat's yield surface is set as 6.0, and the plastic yield expressed with the Hollomon formula, has its properties presented in Table 2.

To stop the test was used the average depth from each experimental test. It was also stipulated that the computational simulation stopped after reaching the preset depth.

\section{Results and discussions}

The stop criteria adopted for the experiments was the rupture in the workpiece. Three experiments were conducted for a single parameter set. For further analysis of the case, where (at least) two specimens ruptured at a similar position, was subsequently investigated. This date also found entrance into FE-Analysis. In Table 3 the final depths are shown for the four tests.

The Argus Measuring Camera, from Gom Company (Optical Measuring Techniques) was used. This camera visualizes the spots that are engraved in the sheet metal and determine the strains. The test specimen analyses were done at the bottom surface of the workpieces, i.e., in the inferior end. A longitudinal line along " $\mathrm{X}$ " coordinate to the

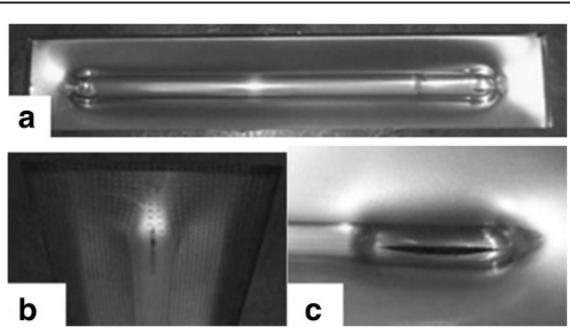

Figure $\mathbf{5}$ Formed samples. a. superior view in the workpiece formed in test \#1; $\mathbf{b}$. inferior view of the rupture in test \#1. c. superior view of the rupture in test \#4. 
Table 2 DC04 material data

\begin{tabular}{|c|c|c|}
\hline \multicolumn{2}{|c|}{ Hollomon formula } & \multirow{2}{*}{$\begin{array}{l}k f=564 \cdot \varphi^{0,2} \\
k f_{0}=186 \mathrm{MPa}\end{array}$} \\
\hline & & \\
\hline \multirow[t]{5}{*}{ Anisotropy } & $\mathbf{r}_{0^{\circ}}$ & 1.16 \\
\hline & $\mathbf{r}_{45^{\circ}}$ & 1.52 \\
\hline & $\mathbf{r}_{90^{\circ}}$ & 1.69 \\
\hline & $\mathbf{r}_{\mathrm{m}}$ & 1.47 \\
\hline & $\Delta r$ & -0.09 \\
\hline
\end{tabular}

strains analyses was traced. In Figure 7, the major and minor main strains are plotted along the test specimen.

The strains imposed by the incremental process are basically the Planar Strain, where all the elongation that the sample suffers is compensated by its thickness. In Figures 5 and 7, it is observed that the ruptures occurred when there is the presence of the minor strain $\left(\varphi_{2}\right)$, since the sample did not present the same strain. In Figure 8 the comparisons between the experimental and the simulated major strains are shown.

The simulation shows an approach with the major strain achieved by the workpiece. The experimental strain peaks found in the graphs come from regions where ruptures in the tested workpiece occurred. The simulation did not anticipate these strain peaks; however, it was in major concordance with the analyses along the workpiece, such as in approximately 0.85 and 0.6 for strain in tests $\# 1$ and $\# 2$, respectively. The main strain peaks were 1.19 and 0.75 in the tests \#1 and \#2, respectively.

In test \#3, for example, it may be considered the same observations of test \#2, where there is a good concordance between the simulation and the experimental results, but it does not anticipate the strain peaks achieved by the sheet in the rupture region. In this test, the main strain in the " $X$ " coordinate center of the workpiece and in the simulation are 0.45 in the experiments; however, the main strain is approximately 0.58 for both cases in the ends of the workpieces. Test \#4 did not show homogeneity in the main strain profile, due to the major severity of the strategy. The strains achieved 0.35 in the simulation and 0.47 in the experiments.

The main strain peaks were measured in the workpiece longitudinal ends, near to the rupture region. As the simulation, which has no failure criterion, does not anticipate these peak values, it is understood that these peaks provoke material rupture.

Another analysis done, referred to the comparison of the strains achieved in the ISF with the conventional FLC. In Figure 9 it can be observed, that the strains in the incremental process are much superior to those of the conventional processes.

Table 3 Final depth in the experiments

\begin{tabular}{cccccccccccc}
\hline Test Sample & $\begin{array}{c}\text { Depth } \\
{[\mathbf{m m}]}\end{array}$ & Test Sample & $\begin{array}{c}\text { Depth } \\
{[\mathrm{mm}]}\end{array}$ & Test Sample & $\begin{array}{c}\text { Depth } \\
{[\mathrm{mm}]}\end{array}$ & Test Sample & $\begin{array}{c}\text { Depth } \\
{[\mathrm{mm}]}\end{array}$ \\
\hline \multirow{3}{*}{$\# 1$} & 1 & 23.0 & & 1 & 22.5 & & 1 & 17.0 & & 1 & 17.5 \\
& 2 & 22.0 & $\# 2$ & 2 & 22.5 & $\# 3$ & 2 & 17.0 & $\# 4$ & 2 & 17.5 \\
& 3 & 23.0 & & 3 & 22.5 & & 3 & 17.0 & & 3 & 20.0 \\
\hline
\end{tabular}




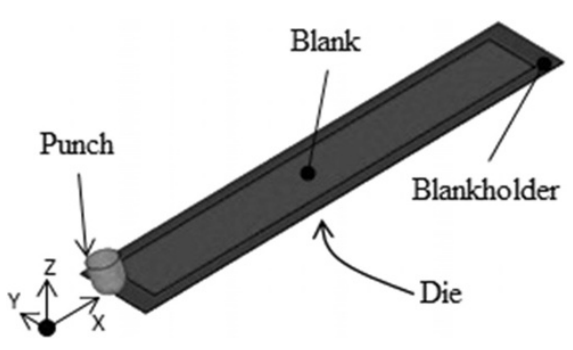

Figure 6 Components assembly in numerical simulation.

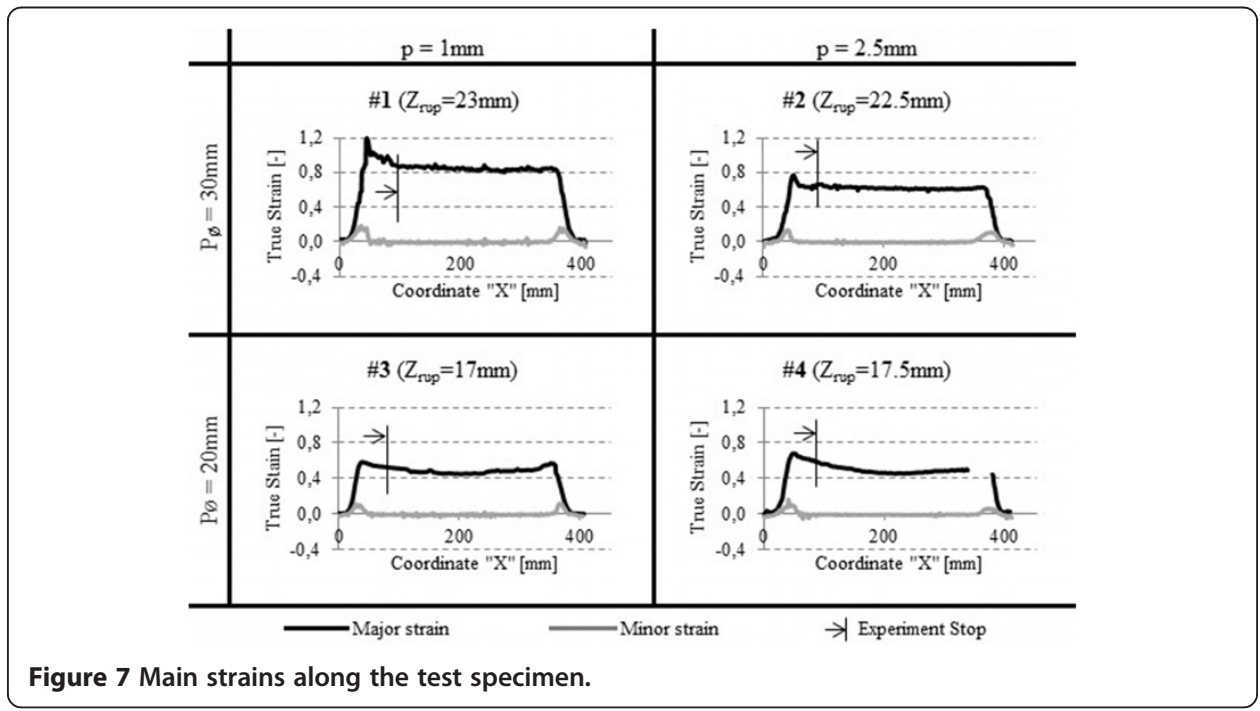

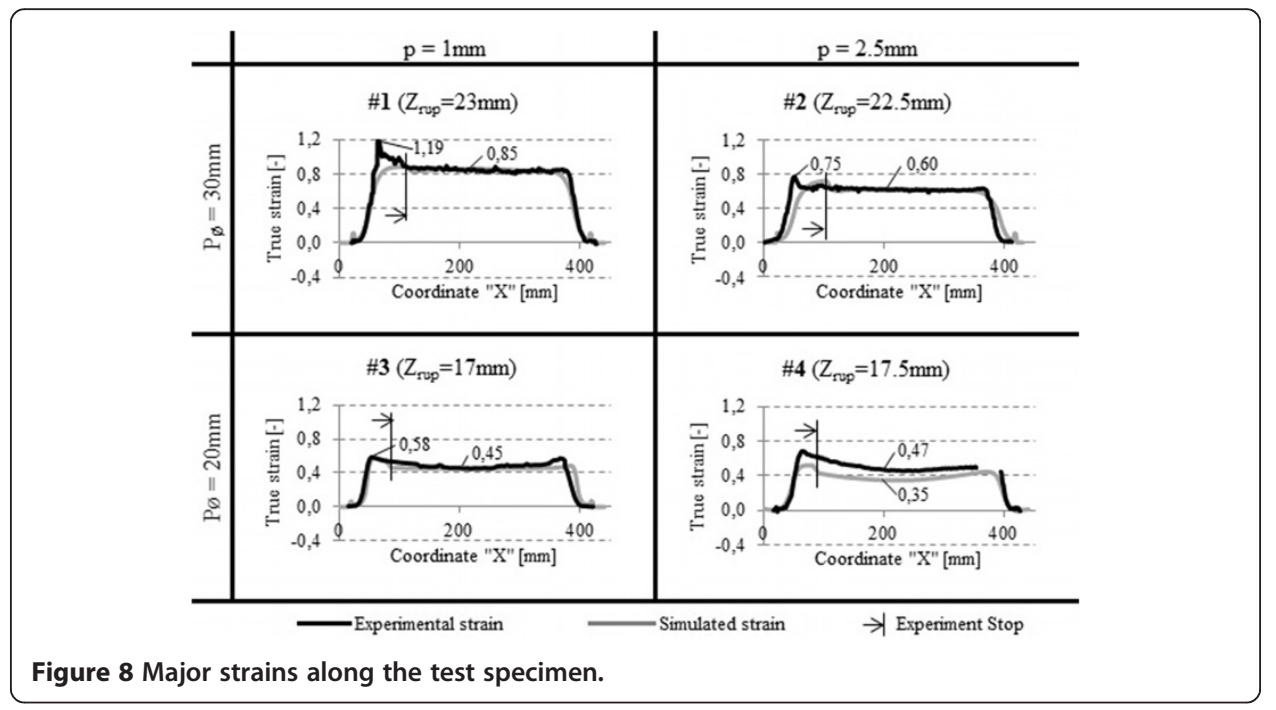




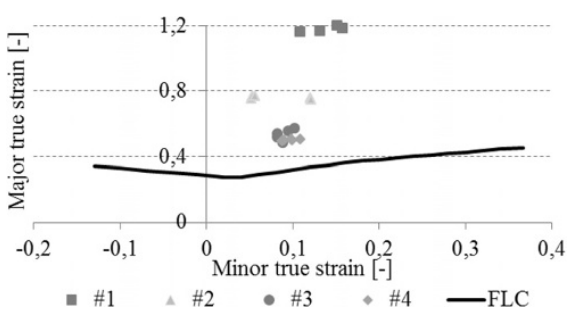

Figure 9 Maximal strain in the near of rupture for the tests\#.

\section{Conclusion}

The strains achieved in test $\# 1$ are higher than the remaining tests and the final depth is larger than in the other tests. A punch with a larger diameter can distribute better the stress over the contact area and make the sheet less severe. Also as a softer increment, it can apply higher strains and larger depth.

In test \#4, it was observed a positive parabola for the strain profile along the test specimen, due to the more severe conditions imposed in the process, consequently, major possibility of springback.

The maximal strain that can be imposed to the sheets in the incremental process vary according to the strategy adopted in the process and cannot apply the strain conventional limits.

\section{Abbreviations}

FEM: Finite Element Method; FLC: Forming Limit Curve; FLD: Forming Limit Diagram; ISF: Incremental Sheet Forming; SPF: Simple Point Forming; TPF: Two Point Forming.

\section{Competing interests}

The authors declare that they have no competing interests.

\section{Authors' contributions}

FAL carried out the experimental studies, participated in the design of the study, performed the statistical analysis and drafted the manuscript. LS participated revising it critically for important intellectual content. Both authors read and approved the final manuscript.

\section{Acknowledgements}

The authors gratefully acknowledge LdTM/UFRGS, SENAI CIMATEC and IBF/RWTH-Aachen for the support in the development of these work and CAPES for the financial support of scholarship.

\footnotetext{
Author details

${ }^{1}$ Manufacturing Processes Area, SENAI IMATEC, Av. Orlando Gomes, 1845, Salvador, Brazil. ${ }^{2}$ Metal Forming Laboratory, Federal University of Rio Grande do Sul, Av. Bento Goncalves 9500, Porto Alegre, Brazil.
}

Received: 11 November 2013 Accepted: 5 January 2014

Published: 22 January 2014

\section{References}

Jeswiet J (2005) Asymmetric incremental sheet forming. Adv Mater Res 6-8:35-58

De Arruda RP (2010) Manufacture of solar collectors plans using incremental sheet forming and welding friction. PhD thesis. Federal University of Rio Grande do Sul, Porto Alegre-BR

Kwiatkowski L, Urban M, Sebastiani G, Tekkaya AE (2010) Tooling concepts to speed up incremental sheet forming Prod Eng-Ger Acad Soc Prod Eng (WGP) 4(1):57-64

Hirt G, Ames J, Bambach M, Kopp R (2004) Forming strategies and process modelling for CNC incremental sheet forming. CIRP Ann-Manuf Technol 53:203-206

Bambach M (2010) A geometrical model of the kinematics of incremental sheet forming for the prediction of membrane strains and sheet thickness. J Mater Process Technol 210:1562-1573

Lora FA, Boff U, Yurgel CC, Folle L, Schaeffer L (2013) Validation of the computer simulation process applied to the incremental forming process for the evaluation of strain paths. Key Eng Mater 554-557:2453-2461

Kopac J, Kampus Z (2005) Incremental sheet metal forming on CNC milling machine-tool. J Mater Process Techno 162-163:622-628 
Silva MB, Alves LM, Alves ML, Martins PAF (2010) Fracture Forming Lines in Single Point Incremental Forming. In: Proc Int Conf. IDDRG, Graz, Austria, pp 451-460

Kuzman K, Tisza M, Petek A, Kovács P (2010) Determination of forming limit diagrams for single point incremental sheet metal forming. In: Proc Int Conf. IDDRG, Graz, Austria, pp 461-468

Jeswiet J, Micari F, Hirt G, Bramley A, Duflou J, Allwood J (2005) Asymmetric single point incremental forming of sheet metal. CIRP Ann-Manuf Technol 54:88-114

Allwood JM, Bramley AN, Ridgman TW, Mileham AR (2006) A novel method for the rapid production of inexpensive dies and moulds with surfaces made by incremental sheet forming. Proc IMechE Part B: J Eng Manuf 220:323-327

Bambach M, Hirt G (2007) Error analysis in explicit finite element analysis of incremental sheet forming. Proceedings of International Numiform 07 Conference, Porto, Portugal, pp 859-864

Dejardin S, Thibaud S, Gelin JC, Michel G (2010) Experimental investigations and numerical analysis for improving knowledge of incremental sheet forming process for sheet metal parts. J Mater Process Technol 210:363-369

doi:10.1186/2196-288X-1-5

Cite this article as: Lora and Schaeffer: Incremental forming process strategy variation analysis through applied strains. Brazilian Journal of Science and Technology 2014 1:5.

\section{Submit your manuscript to a SpringerOpen ${ }^{\circ}$ journal and benefit from:}

- Convenient online submission

Rigorous peer review

- Immediate publication on acceptance

- Open access: articles freely available online

- High visibility within the field

- Retaining the copyright to your article

Submit your next manuscript at $\gg$ springeropen.com 